\title{
Design \& Implementation of an Automated Protective Film Applying Machine for the Aluminum Fabrication
}

\author{
S.V.A.S.H. Ariyathunge \\ Department of Mechanical Engineering \\ The Open University of Sri Lanka \\ Nugegoda, Sri Lanka
}

\author{
H.M.K.K.M.B. Herath \\ Department of Mechanical Engineering \\ The Open University of Sri Lanka \\ Nugegoda, Sri Lanka
}

\author{
A.C.G Perera \\ Department of Mechanical Engineering \\ The Open University of Sri Lanka \\ Nugegoda, Sri Lanka
}

\begin{abstract}
Aluminum is the third most abundant element in the nature and extrusion is valuable due to commercial fenestration and manufacturing products. Aluminum profiles are causing severe damage during the fabrication and installation process. Sawing, drilling, and tapping are the most common mechanical damages cause in aluminum profiles when subjected to the organic coating. Aluminum is interacting with the Alkali Hydroxides $\left(\mathrm{Ca}(\mathrm{OH})_{2}, \mathrm{NaOH}, \mathrm{KOH}, \mathrm{RbOH}\right.$, and $\mathrm{CsOH}$ ) during the cement-based installation process [1]. There are several companies that involving to the manufacturing of aluminum profiles in Sri Lanka. In Sri Lanka, the film applying process of aluminum profiles is carried out by human hand. Due to this problem, companies are looking for solutions to minimize time consumption and cost.
\end{abstract}

The aim of this study is to find a possible solution and design a machine to protect the surface of the aluminum profiles. The objective is to minimize the time consuming and cost-effective method for the film application process. The system was tested with different profile shapes and results were analyzed with the existing manual method. We observed that the designed machine was $87.04 \%$ more efficient than the manual existing method in Sri Lanka.

Keywords:- Motor control, Alkali hydroxide, PLC, Organic coating, Aluminum fabrication, Motor drives, Microcontroller.

\section{INTRODUCTION}

Aluminum is known as an alloy which is commonly used in various areas such as aircraft industry, construction industry, electricity, packaging, transportation and medicine [2]. The Aluminum Association states that the aluminum was considered more rare and precious than silver or gold in $19^{\text {th }}$ century [3]. A pure form of metal was successfully extracted from ore in 1825 by Hans-Christian. It has gone on a marvelously stimulating expedition from an invaluable metal to the material used virtually in every scope of human life in just one and a half centuries. Aluminum began to be used in various ways at the turn of the 19th and 20th centuries which created an incentive for development in a new range of industries [4].
Aluminum alloys are which aluminum is employed as a major metal along with Copper, magnesium, manganese, silicon, tin and zinc [5]. Casting alloy can be used in manufacturing cost effective product due to its low melting point.

Annually 45 million tons of semi-fabricated aluminum is produced, including approximately 14 million tons from recycled aluminum [6]. The global manufacturing of aluminum in 2016 was recorded as 58.8 million metric tons. It passed over that of another metal except for iron $(1,231$ million metric tons) [7]. No other metal can compare to Aluminum when it comes to its multifarious uses. The most common uses of aluminum in Sri Lanka are transportation, construction, electrical, and consumer goods [8]. Extruded aluminum is widely used in the building because of its intrinsic properties of lightness and corrosion resistance. Aluminum is use in external facades, roofs, walls, windows, doors, staircases, railings, shelves and other several applications [9].

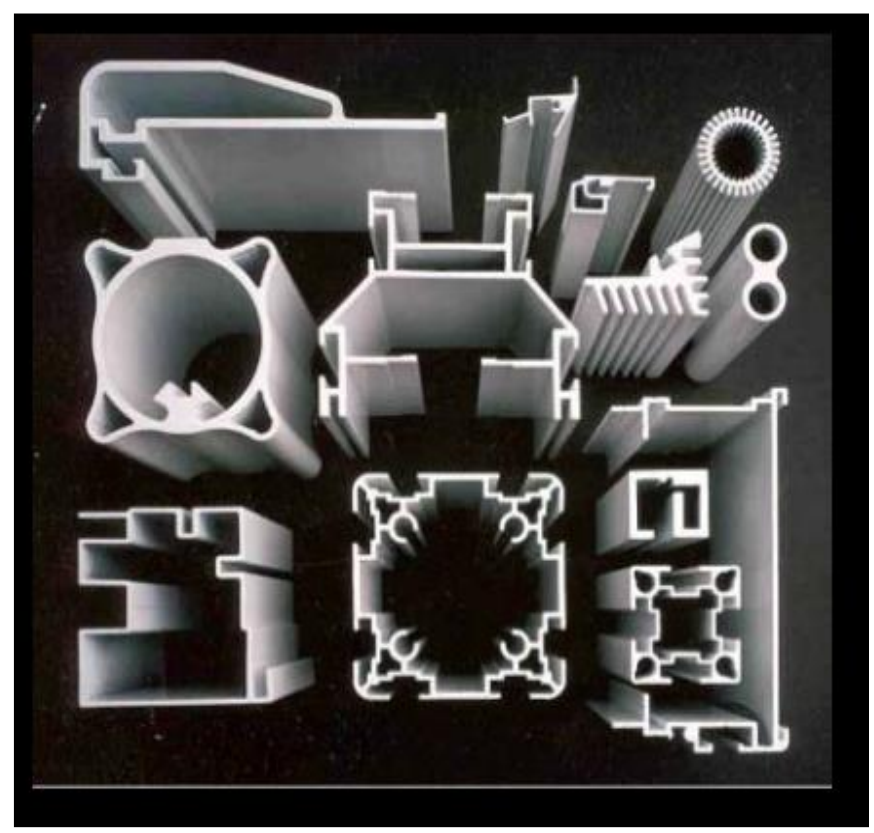

Fig 1:- Different Shapes of Profiles Used in Industry [10].

Aluminum fabrication is the process of shaping aluminum into a finished product, such as windows, doors, louvers, or an outdoor enclosure. Fabrication of aluminum spans a wide field of processes, including sawing, drilling, 
and threading [11]. During fabrication processes, the organic coating of aluminum profile can suffer from mechanical damage and unprotected aluminum interacts with cement-based materials during the installation of fabricated items in the building. In fresh concrete, aluminum reacts principally with alkali hydroxides from cement [1].

\section{LITREATURE REVIEW}

Model PTA 250 is a machine for the applying of protection tape, film, or foil on the aluminum profiles. It applies the protective tape on the surfaces of profiles passing one after the other in line. Two driving pairs of vulcanized and rectified rollers of independent drive assure the infeed and exit of the taped profiles in a controlled independent way. The protection sticking film rolls are posted on the machine simply and quickly (Two vertical ones have been held from their perimeter/ five horizontal and four vertical fixed freerolls for the support of the moving profiles/ two moving vertical freerolls for the guidance of profile)[12].

The machinery is in particular designed to allow for the applying of adhesive film or tape on several types of aluminum profiles, on four independent sides (Top, Bottom, Left, and Right side) and it is created of a frame in tubular sectioning, with four pneumatic expansion reel units (spoolers), complete with automatic film tension-regulation system. Adhesive tape cutting unit between the profiles is made up of a pneumatic electric unit with a circular blade. This is the system called "Continuous on-the-fly cut" because it follows and works between the spaces between the profiles (Head - Tail) in order to have a constant production speed [13].

Moretto Extruding machine which was projected and built by CMF Moretto to pack, package, and wraps objects or items of different shapes and sizes (such as frame and match-board rods, flat profiles of linear or shaped). The aluminum profiles are carried out through a polyethylene film with hot extrusion which can be adjusted working speed and thickness of the film [13]. Main drawbacks of these three systems are highly expensive, takes up more space, and difficult to change roller angle or direction quickly to fit profile shapes.

\section{METHODOLOGY}

This study was conducted to invent a possible solution to protect the surface of aluminum profiles by using mechanical and control theories. The prototype was capable to save expensive for reworking and reduce unnecessary production losses during the fabrication and installation processes in industry.

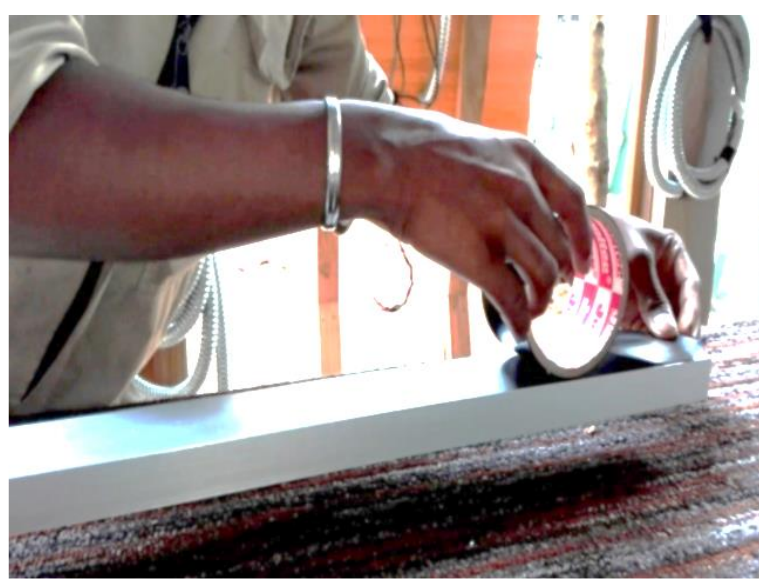

Fig 2:- Manual Operation of Film Applying Process

In Sri Lanka, aluminum fabrication industries are adding protective tapes for aluminum profiles by manual process. Fig. 2 illustrates the applying of protective film for an aluminum profile by an employee in the industry. Employees were adapting to applying protective films which are in different size and shape for the different requirements.

Traditional process was conducted in manual operation and protective tape applying process for 150 aluminum profiles (6.5 m length) was used in this study. Required walking distance per day for 150 aluminum profiles (taped on three sides of a profile) is,

Walking distance per day $=6.5 \mathrm{~m} \times 3 \times 150 \times 2=\mathbf{5 8 5 0} \mathbf{m}$

During the process, a worker consumes 50 seconds for a complete taping process on one side of a profile (length of profile is $6.5 \mathrm{~m}$ ) and most workers felt tired often and they couldn't apply the tape properly on the line of the profile. Table I depict the time consumption of the existed method.

\begin{tabular}{|c|c|c|c|}
\hline \multirow{2}{*}{ Process } & \multicolumn{3}{|c|}{ Time Spend (seconds) } \\
\cline { 2 - 4 } & One side & $\begin{array}{c}\text { Three } \\
\text { sides }\end{array}$ & $\begin{array}{c}150 \\
\text { profiles }\end{array}$ \\
\hline Applying & 50 & 150 & 22500 \\
\hline Cutting & 3 & 9 & 1350 \\
\hline Placing Profiles & & 7 & 150 \\
\hline \multicolumn{3}{|c|}{ Total Time Spend } & 24900 \\
\hline
\end{tabular}

Table 1:- Time Taken to Complete the Each Process

The method of the development of this study is comprised with four main steps.

$>$ Development of a possible design which is able to protect the surface of the aluminum profiles.

$>$ Design a mechanical and electronic system.

$>$ Development of a system to protect the surfaces of the aluminum profiles.

$>$ Analysis of results from the system and incorporates modifications. 
ISSN No:-2456-2165

\section{A. Force Required to Remove Adhesive Tape from the Roller}

Adhesive tapes are consisting of backing material with a thin layer of adhesive on it which may alter its chemical composition. The chemical substance of adhesive is made from polymers. To remove the tape, the pulling force requires overcoming the adhesion energy in between the tape and the surface of aluminum profile.

\begin{tabular}{|c|c|}
\hline Trial Number & Reading of the Spring / (g) \\
\hline 1 & 725 \\
\hline 2 & 729 \\
\hline 3 & 724 \\
\hline 4 & 725 \\
\hline 5 & 727 \\
\hline
\end{tabular}

Table 2:- Force Required to Remove the Tape

The force requires to remove the tape is varied according to the speed and way of pulling. Therefore, an experiment was conducted under the gravitational acceleration. Fig. 3 demonstrates the experimental arrangement for the calculation of force which required removing the tape. This experiment was carried out for the PVC (Polymerizing Vinyl Chloride) tape with a $30 \mathrm{~mm}$ width and $0.04 \mathrm{~mm} \pm 0.005 \mathrm{~mm}$ thickness.

Average of readings $=726 \mathrm{~g}$

\section{The force required to remove the tape $=726 \times 10^{-3} \times 10 \mathrm{~N}$ $=7.26 \mathrm{~N}$}

Table 2 depicts the results of the experiment for five trials and the average of the reading was found $726 \mathrm{~g}$. According to the results, we observe that the force required to remove tape was $7.26 \mathrm{~N}$.

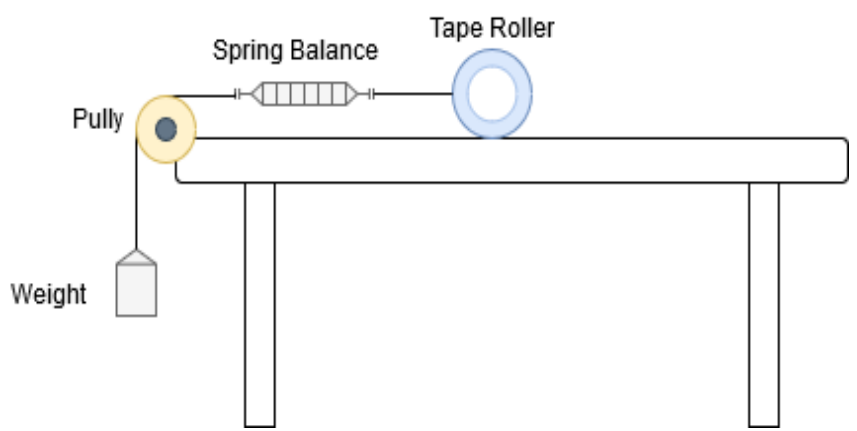

Fig 3:- Testing Configuration for Calculate the Minimum Force

\section{B. Mechanical Designof the System}

Mechanical Design describes the calculation criteria of the required mechanical components of the prototype. Analysis and the design study of the carrier and clamping systems of the prototype are shown in Fig. 4. Function and components of the both Carrier and Clamping units are described in Table 3.

\begin{tabular}{|c|c|c|}
\hline Sub System & Function & Components \\
\hline Carrier Unit & $\begin{array}{l}\text { Move Holder on } \\
\text { Horizontal }\end{array}$ & $\begin{array}{c}\text { Motor, Tape holder } \\
\text { Freely rotatable roller } \\
\text { Open ended belt drive } \\
\text { Gear unit } \\
\text { Guide rail } \\
\text { Bearings }\end{array}$ \\
\hline $\begin{array}{c}\text { Clamping } \\
\text { Unit }\end{array}$ & $\begin{array}{c}\text { Clamp the } \\
\text { Aluminum Profile }\end{array}$ & $\begin{array}{c}\text { Grippers } \\
\text { Pneumatic cylinders } \\
\text { Solenoid }\end{array}$ \\
\hline
\end{tabular}

Table 3:- Function of the Componenet in Sub-Systems

Carrier unit includes a linear moving system which is placed on a base with guided rails. The rotational moving system includes two parts for hold the PVC tape and rotatable roller. Fig. 5 shows the linear moving system and the rotational moving system of the prototype. Rotatable rollers are made with Polyurethane Rubber (thickness of 30 $\mathrm{mm}$ and width $130 \mathrm{~mm}$ ) surface with Nylon Fibers. Polyurethane Rubber surface helps to reduce the air bubbles between extruded aluminum profile and the Polyvinyl Chloride $\left[\left(\mathrm{C}_{2} \mathrm{H}_{3} \mathrm{Cl}\right)_{n}\right]$ tape during the taping process. In the taping process, two grippers were attached to the double acting pneumatic cylinders which were acted as the clampers for the aluminum profile.

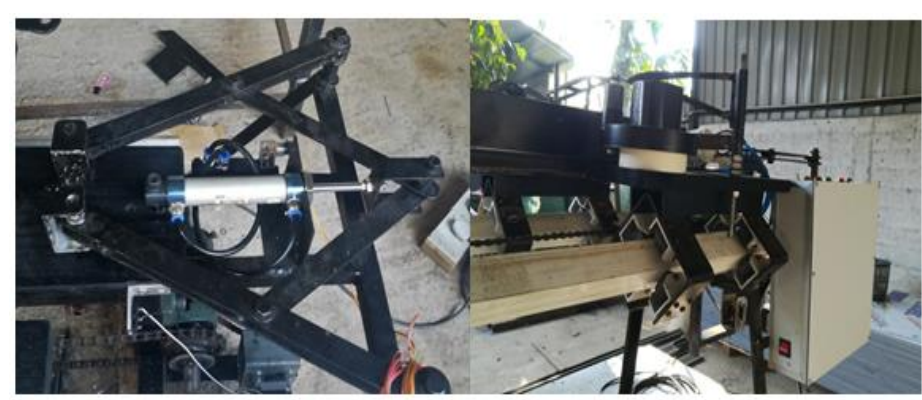

Fig 4:- Clamping Unit and Carrier Unit of the Prototype Left: Clamping Unit Right: Carrier Unit

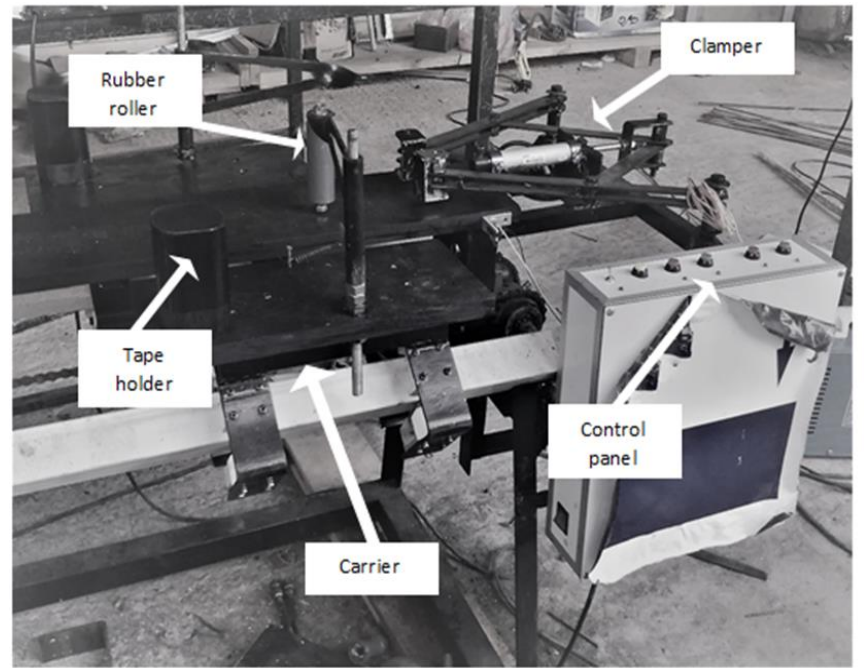

Fig 5:- Linear Moving System and Rotational Moving System 


\section{Electrical and Control System Design}

External view of the control system with inputs and outputs is shown in Fig. 6. Electronic components and control requirements were identified in order to develop the control system. For this study Start button, Position sensor, Clamping switch and two Proximity sensors were passed signals to the microcontroller. The microcontroller was controlled the motor drive and solenoids according to the decisions generated by the controller.

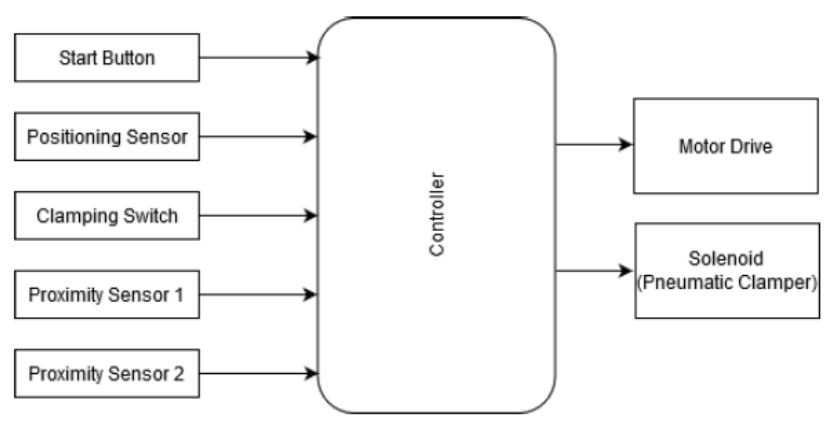

Fig 6:- External View of the System

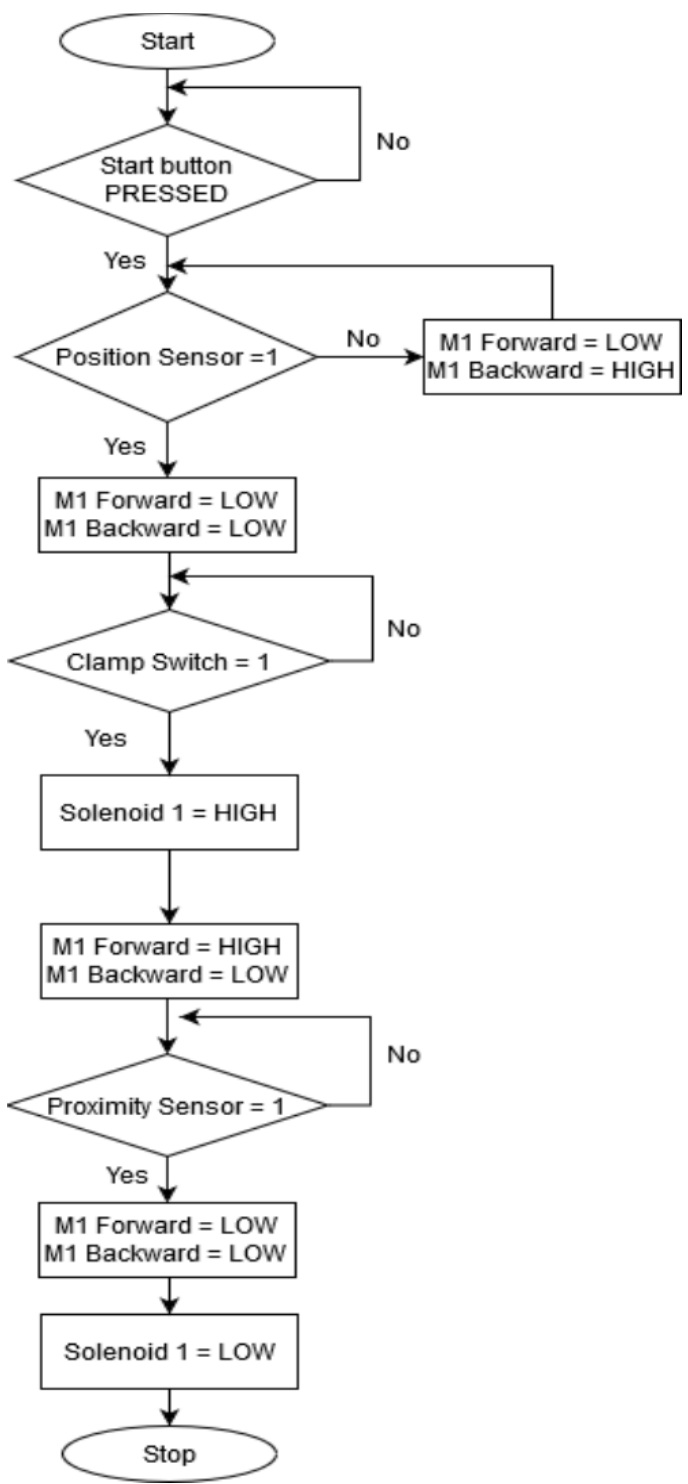

Fig 7:- Program Flowchart of the Control System
Identification of input and output requirements,

$\begin{array}{ll}P L C \text { analog inputs } & =4 \\ \text { High speed outputs (for motor drives) } & =2 \\ \text { PLC outputs } & =4\end{array}$

By considering the required response time of the PLC, Required response time $=50 \mathrm{~ms}$

To detect the profile,

No of instruction sets $\quad=642$

Total execution time $\quad=(642 \times t p) \mu \mathrm{s}$

$\mathrm{I} / \mathrm{O}$ response time $\quad=20 \mu \mathrm{s}$

Total cycle time $\quad=(642 \times t p)+20 \mu \mathrm{s}$

Response time of the sensor $\quad=500 \mu \mathrm{s}$

Response time to detect the profile $=1162 \times t p \mu s$

Available response time $\leq$ Required response time $520+(642 \times t p \mu s) \leq 50 \mathrm{~ms}$

tp $\leq 77 \mu \mathrm{s}$

According to the calculation, required response time of the PLC was found $77 \mu$ s and frequency was $13 \mathrm{mHz}$. When the operator presses the Start Button, Position sensor reads the current position of the carrier. When the carrier is not at initial position, the motor begins to run on backward direction until the carrier is placed in the initial position. When the operator placed the profile, clamp switch is turned to $\mathrm{ON}$ state and the solenoid is turned to ON state. The motor is running on forward direction until the film applying process complete.

The film application process is fully mechanical. When the proximity sensors were detected the carrier, the motor, solenoid, and proximity sensors were turned to off. With this application, Proximity sensors were worked as the safety precaution. Fig. 7 shows the program flowchart of the control system of the prototype.

D. Desired Motion of the Carrier

For the calculations, Newton's equations of motions [14] were used,

Maximum constant speed of the carrier,

Displacement of the carrier $\quad=u t$

Required Initial velocity $\quad=1.5 \mathrm{~ms}^{-1}$

Final Velocity $=$ Required Initial Velocity $+($ Acceleration of the carrier $\times$ Time)

Maximum constant speed of the carrier $(u)$,

$u=1.5 \mathrm{~ms}^{-1}$

Acceleration of the carrier $\left(a_{a c}\right)$,

$a_{a c}=0.75 \mathrm{~ms}^{-2}$

Deceleration of the carrier $\left(a_{d e}\right)$,

$a_{d e}=-0.75 \mathrm{~ms}^{-2}$ 
The force necessary to accelerate the carrier $\left(F_{a}\right)$ Applying Newton's second law,

Applying 5kg test load to carrier,

$F_{a}=(5 \times 0.75) N$

$F_{a}=3.75 \mathrm{~N}$

\section{Rolling resistance}

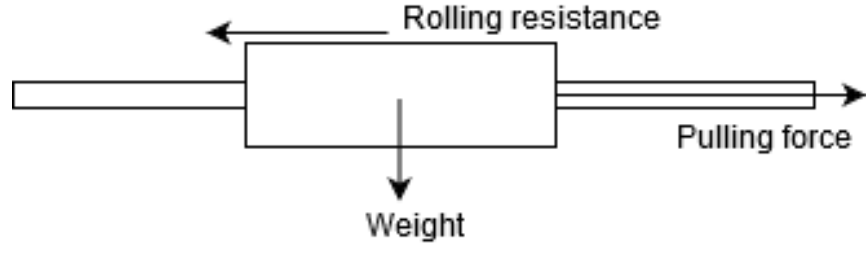

Fig 8:- Forces Acting on the Carrier Unit

Rolling resistance [15] of the carrier $\left(F_{r}\right)$,

$F_{r}=C \times W$

Where,

$F_{r}=$ Rolling resistance

$C=$ Coefficient of rolling resistance

(0.2 for steel and Polytetrafluoroethylene) [16]

$W=$ Weight of the carrier

$m=$ Mass of the carrier (test load $m=5 \mathrm{~kg}$ )

$a_{g}=$ Acceleration due to the gravity

$W \quad=m \times a_{g}$

$=5 \times 9.81 \mathrm{kgms}^{-2}$

$=49.05 \mathrm{kgms}^{-2}$

Substituting to equation,

$F_{r} \quad=C \times W$

$=0.2 \times 49.05 \mathrm{~N}$

$=9.81 \mathrm{~N}$

The force required to remove the tape $\left(F_{t}\right)=\left(7.26 \times S_{f}\right) N$

At, $S_{f}$ (Safety Factor) $=2$ [17]

Total force $(F)$,

$$
\begin{aligned}
F & =F_{a}+F_{r}+\left(7.26 \times S_{f}\right) \\
& =(3.75+9.81+14.52) \mathrm{N} \\
& =28.08 \mathrm{~N}
\end{aligned}
$$

Load torque $\left(T_{L}\right)$,

Where, $\mathrm{r}$ is radius of the selected pulley $(r=30 \mathrm{~mm})$

$T_{L}=F \times r$

$T_{L}=28.08 \times 0.03 \mathrm{Nm}$

$T_{L}=0.8424 \mathrm{Nm}$

Required torque $\left(T_{m}\right)$,

$T_{m}=T_{L} \times S_{f}$

$T_{m}=0.8424 \times 2 \mathrm{Nm}$

$=1.6848 \mathrm{Nm}$
Required angular velocity,

$$
\omega_{m}=\frac{V}{r}=\left(\frac{1.5}{0.03}\right) \operatorname{rads}^{-1}=\mathbf{5 0 \mathbf { r a d s } ^ { - 1 }}
$$

$$
\begin{aligned}
n=60 \times & \left(\frac{\omega_{m}}{2 \pi}\right) \\
& =60 \times\left(\frac{50}{2} \times 3.14\right)=478 \mathrm{rpm}
\end{aligned}
$$

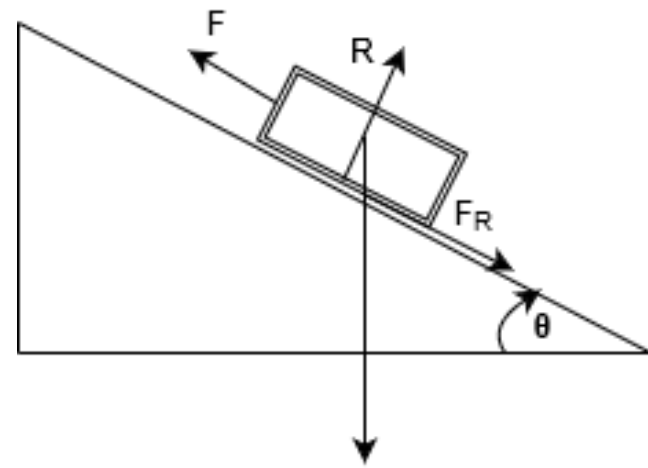

$\mathrm{Mg}+\mathrm{F}_{\text {ext }}$

Fig 9:- Free Body Diagram of Motor Shaft

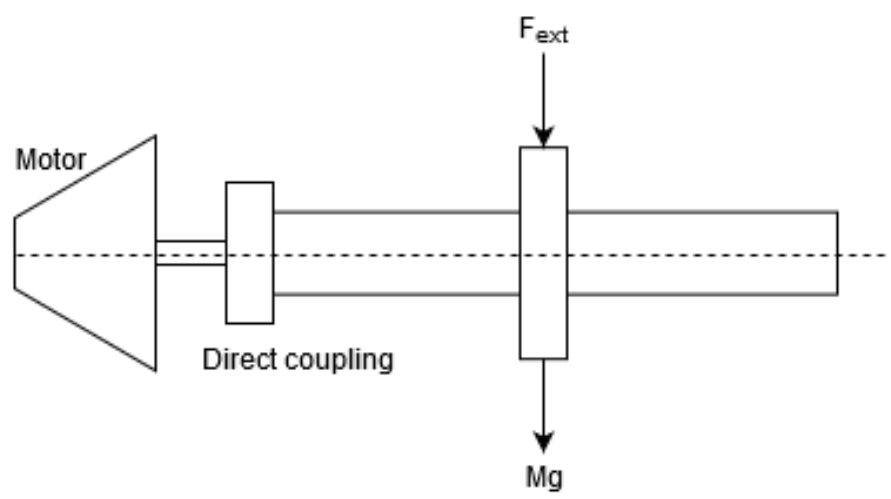

Fig 10:- Coupling of Motor Shaft with Gear Wheel Shaft

\section{E. Motor Selection}

Applying Newton's second law in along the plane,

Where,

$F_{\text {ext }} \quad=$ External force on the pulley

$M \quad=$ Mass of the pulley

$F_{r} \quad=$ Friction force

Coefficient of friction is 0.5 between metals and polyurethane [18]

$$
R=\left(M g+F_{\text {ext }}\right) \times \cos \theta
$$

Applying Newton's second law perpendicular to the plane,

$$
\begin{gathered}
F=\mu R+\left(M g+F_{\text {ext }}\right) \sin \theta \\
F=\mu\left(M g+F_{\text {ext }}\right) \cos \theta+\left(M g+F_{\text {ext }}\right) \sin \theta
\end{gathered}
$$


at $\theta=0$

$$
F=(12.26+28.08) \cos 0+(12.26+
$$

28.08) $\sin 0$

$$
F=40.34 N
$$

Load Torque $\left(T_{L}\right)$

$T_{L}=F+T_{\text {fric }}$

Where, $T_{\text {fric }}$ is the frictional force of the motor shaft due to rotation.

Assuming it as zero and considering the maximum $r=0.03 \mathrm{~m}$,

$T_{L} \quad=40.34 \times 0.03$

$=1.21 \mathrm{Nm}$

Required Torque $\left(T_{m}\right)$,

$T_{m}=T_{L} \times S_{f}$

At, $S_{f}=2$;

$T_{m}=1.21 \times 2=\mathbf{2 . 4 2} \mathbf{N}$

\section{RESULTS}

Machine operating time was obtained by conducting several work studies. Three work-studies were carried out to obtain the operating time of the prototype for applying tape and the results were defined as a cycle time for single profile.

In the first work study, machine was operated by an unskilled operator in the workshop environment. Cycle time was taken as $\boldsymbol{T}_{c y l l}$ for one profile and then repeated the process for five cycles. As the result $T_{c y l l}$ was calculated by, average value for cycle time for the five cycles.

$$
T_{c y l 1}=\frac{\left(\in_{i=1}^{5} \times T_{i}\right)}{5}=21 \mathrm{sec}
$$

The second work study was made in a production environment in "Tudawe Engineering Services Pvt. Ltd - Sri Lanka". Two machine operators were assigned to obtain the cycle time. One operator was a skilled operator and other operator was an unskilled operator. $T_{c y l 2}$ and $T_{c y l 3}$ respectively denote the average cycle time which obtained from unskilled operator and skilled operator. Whole processes were repeated for five cycles and the average was calculated.

$$
\begin{aligned}
& T_{c y l 2}=\frac{\left(\in_{i=1}^{5} \times T_{i}\right)}{5}=23 \mathrm{sec} \\
& T_{c y l 3}=\frac{\left(\epsilon_{i=1}^{5} \times T_{i}\right)}{5}=19 \mathrm{sec}
\end{aligned}
$$

The bar chart (Fig. 11) illustrates the time consumption to apply tape to the aluminum profile between existing and suggested method (Film Applying Prototype). The average cycle time of the fabrication prototype was taken by using both unskilled $\left(T_{c y l 2}\right)$ and skilled $\left(T_{c y l 3}\right)$ operators. Skilled operator has previous knowledge about applying tape by using automated machine (by following training about fabrication prototype). Unskilled operator has not previous knowledge of using the prototype.

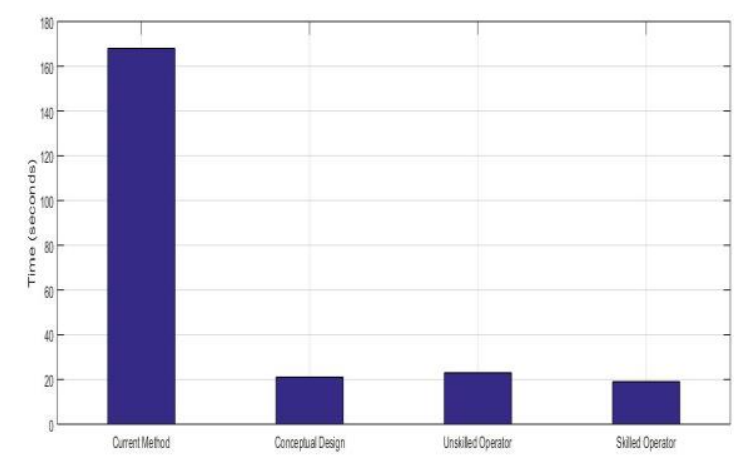

Fig 11:- Cycle Time (time taken to tape one profile)

\section{CONCLUSIONS}

This study was conducted to design and implement a prototype for protective tape applying mechanism to the aluminum profiles. The prototype was tested in real time application of the aluminum fabrication industry. Time consumption was calculated with the existing method versus fabrication prototype. We observe that, the prototype was $87.04 \%$ more efficient than the existing method. The prototype was designed for the ease of use with the operator and with the safety precautions. According to the test results, the operator does not require highly skilled to do the work in efficient. Whether, the operator is skilled person or unskilled person the efficiency of the work is higher than the existing method.

\section{REFERENCES}

[1]. PCA - The Portland Cement Association - America's Cement Manufacturer. [Online]. Available: https://www.cement.org/. [Accessed: 20-Jun-2020].

[2]. "History of aluminium," Wikipedia, 08-Jun-2020. [Online]. Available: https://en.wikipedia.org/wiki/History_of_aluminium. [Accessed: 20-Jun-2020].

[3]. A. Ambroziak and M. Solarczyk, "Application and mechanical properties of aluminium alloys," Shell Structures: Theory and Applications Volume 4, pp. 525-528, 2017.

[4]. "History of Aluminum," History of Aluminum | The Aluminum Association, 17-Jun-2020. [Online]. Available: https://www.aluminum.org/aluminumadvantage/history-aluminum. [Accessed: 20-Jun2020].

[5]. D. Prakash, R. Mariappan, J. Anand, D. Sundar, and K. Dinesh, "A Review On Latest Development Of Aluminium Alloy Metal Matrix Composite Through 
Powder Metallurgy Route ," International Journal of Mechanical and Production Engineering Research and Development (IJMPERD) , pp. 235-241, May 2012.

[6]. S. K. Das and W. Yin, "The worldwide aluminum economy: The current state of the industry," Jom, vol. 59, no. 11, pp. 57-63, 2007.

[7]. T.J Brown, N.E Idoine., E.R Raycraft, R.A Shaw, S.F Hobbs, P. Everett, E.A Deadyand T. Bide, "World Mineral Production 2012-16", British Geological Survey. Keyworth, Nottingham,2018.

[8]. "Most Common Uses of Aluminum," Metal Supermarkets - Steel, Aluminum, Stainless, HotRolled, Cold-Rolled, Alloy, Carbon, Galvanized, Brass, Bronze, Copper, 08-Feb-2019. [Online]. Available: https://www.metalsupermarkets.com/common-usesaluminum/. [Accessed: 17-Jun-2020].

[9]. "Aluminium rolled products supplier: Laminazione Sottile" Aluminium rolled products supplier | Laminazione Sottile. [Online]. Available: https://www.laminazionesottile.com/. [Accessed: 17Jun-2020].

[10]. "Extrusion," Eagle Aluminum Group. [Online]. Available: http://eaglealum.com/extrusion.html. [Accessed: 22-Jun-2020].

[11]. Person, Custom Manufacturing \& Fabricating Articles on Thomasnet. [Online]. Available: https://www.thomasnet.com/articles/custommanufacturing-fabricating. [Accessed: 17-Jun-2020].

[12]. Protective Tape Film Application Machine Aluminium Extrusions Profiles Extruded. [Online]. Available: http://www.noktametal.com/pta250en.htm. [Accessed: 17-Jun-2020].

[13]. A. Z, "Extrusion system," CMF Moretto. [Online]. Available: http://www.cmfmoretto.com/en/products/extrusionsystem. [Accessed: 17-Jun-2020].

[14]. "Equations of motion," Wikipedia, 09-May-2020. [Online]. Available: https://en.wikipedia.org/wiki/Equations_of_motion. [Accessed: 17-Jun-2020]

[15]. Tires and passenger vehicle fuel economy: informing consumers, improving performance. Washington, D.C: Transportation Research Board, 2006.

[16]. "MHI - The Industry That Makes Supply Chains Work," Leading trade association for the material handling, logistics and supply chain industry - The Industry That Makes Supply Chains Work. [Online]. Available: https://www.mhi.org/. [Accessed: 17-Jun2020].

[17]. "Factors of Safety," Engineering ToolBox. [Online]. Available:

https://www.engineeringtoolbox.com/factors-safetyfos-d_1624.html. [Accessed: 17-Jun-2020].

[18]. "Friction and Friction Coefficients," Engineering ToolBox. [Online]. Available: https://www.engineeringtoolbox.com/frictioncoefficients-d_778.html. [Accessed: 18-Jun-2020]. 